\title{
Avaliação do Diferencial de Salários na Agropecuária Brasileira: Período de 1966 a $2002^{*}$
}

\author{
Jefferson Andronio Ramundo Staduto** \\ Mirian Rumenos Piedade Bacchi*** \\ Carlos José Caetano Bacha*
}

Sumário: 1. Introdução; 2. Arcabouços teórico e metodológico; 3. Resultados empíricos; 4. Conclusões.

Palavras-chave: diferença de salários; salários agrícolas; mercado de trabalho; migração; co-integração.

Código JEL: Q1.

Este artigo avalia as tendências, ao longo do tempo, do diferencial de salários entre os trabalhadores da agropecuária brasileira. Para tanto, esses trabalhadores são divididos em permanentes e temporários. Dados semestrais de salários para o período de 1966 a 2002 e procedimentos econométricos de co-integração, mais especificamente a metodologia de Johansen, são utilizados. Os resultados indicam que não há co-integração dos salários dos trabalhadores permanentes entre as regiões do Brasil, mas constata-se alto grau de co-integração dos salários médios dos trabalhadores permanentes entre os estados de cada região. Neste segmento do mercado trabalho agrícola, as diferenças salariais entre as regiões são dispersas ao longo do tempo e somente nos anos 90 esta dispersão e as flutuações são reduzidas sensivelmente. Os resultados da análise sobre o comportamento dos salários dos trabalhadores temporários evidenciam a região Nordeste como a grande arbitradora de salário em relação às demais regiões, o que se explica pela grande mobilidade de mão-de-obra sazonal do Nordeste com destino às demais regiões. Os salários dos trabalhadores temporários das regiões Sudeste, Sul e Centro-Oeste também apresentaram relações de co-integração, provavelmente devido ao efeito de arbitragem pro-

\footnotetext{
*Artigo recebido em abr. 2003 e aprovado em fev. 2004. Uma primeira versão deste trabalho, considerando dados de 1966 a 1999, foi apresentada no II Seminário de Economia Aplicada IPEA/UnB/MTE sobre Diferencial de Salários no Brasil, o qual foi realizado em Brasília, DF, de 06 a 08 de novembro de 2002. O presente trabalho considerou o período de 1966 a 2002. Apesar dos dados terem amplitudes diferentes, as conclusões dessas duas versões do trabalho são similares.

${ }^{* *}$ Professor adjunto da UNIOESTE. E-mail: staduto@unioeste.br

*** Professora Doutora da ESALQ/USP. E-mail: mrpbacch@esalq.usp.br

${ }^{* * * *}$ Professor Associado da ESALQ/USP. E-mail: cjcbacha@esalq.usp.br
} 
veniente da região Nordeste. Entretanto, as diferenças salariais dos trabalhadores temporários entre as regiões flutuaram bastante até meados da década de 1980, e a maior amplitude de diferença salarial é da região Nordeste em relação às demais, superando em muito as diferenças observadas para os trabalhadores permanentes.

This paper evaluates long-term trends of wage differences among Brazil's rural workers. The later are divided into two groups, permanent and temporary workers. Johansen's co-integration methodology and 1966 through 2002 data set, organized by semester averages, are used in this paper. There are two major conclusions. First, there is no co-integration among Brazilian permanent workers' wages when Brazil's regions are compared; however, there is high co-integration among permanent workers' wages inside each region. Permanent workers' wage differences were large until the late of 1980s, reducing significantly during the 1990s. Second, there is high co-integration among Northeastern temporary workers' wages and other regional wages. It implies that Northeastern workers arbitrate temporary workers' wages in other regions. It happens because there is large mobility of temporary labor from Northeast to other regions. Temporary workers' wages at Center-West, South and Southeast have co-integration, probably, because Northeastern workers arbitrate their temporary workers' wages. In spite of these co-integration relations among temporary workers' wages, there is large difference among them. Northeastern workers' wages are below the wages paid in other regions.

\section{Introdução}

O objetivo deste trabalho é examinar, ao longo do tempo, as tendências do diferencial de salários entre os trabalhadores da agropecuária brasileira. Para tanto, eles são classificados em trabalhadores temporários e permanentes. A análise agrega os salários desses trabalhadores por estados e, em seguida, por regiões do Brasil.

O mercado de trabalho agrícola sofreu grandes modificações a partir da década de 60 do século passado. De 1960 a 1985 houve grande crescimento da mão-de-obra assalariada temporária, e a partir de então tem crescido a importância da mãode-obra assalariada permanente. A análise da evolução do uso de mão-de-obra na agropecuária brasileira já foi feita por diversos autores. Goodman et alii (1985) ressaltou as formas de trabalhadores assalariados disfarçados que ocorreram até a década de 60 do século XX. Mello (1975), Brant (1979), Cacciamali (1986) e 
Aguirre e Bianchi (1989) dedicaram-se a explicar as razões pela qual surgiram e ampliaram os trabalhadores temporários na agropecuária brasileira a partir de meados da década de 60. A partir de meados da década de 80 começou a reduzir o uso de trabalhadores temporários na agropecuária brasileira, aumentando a importância do uso de trabalhadores permanentes. Essa modificação é condizente com o processo de modernização da agropecuária, o qual demanda mão-de-obra mais qualificada, a qual é classificada como trabalhadores permanentes (Staduto et alii, 2002c).

Apesar da perda de importância econômica da agropecuária na composição do PIB brasileiro nas últimas quatro décadas, esse setor ainda é grande absorvedor de mão-de-obra. Em 1999, a agropecuária detinha $24 \%$ da População Economicamente Ativa (PEA) nacional (IBGE, 1999). Trata-se de um setor que absorve um número expressivo de trabalhadores não-qualificados.

A agropecuária emprega volume expressivo de mão-de-obra apesar de seu intenso processo de modernização. Esse processo, que se intensificou a partir de meados da década de 60 , resultou em consistente aumento da produtividade total dos fatores (Ávila e Evenson, 1995, Gasques e Conceição, 1997, Dias e Bacha, 1998, Conceição, 1998, Barros, 1999). As medidas parciais de produtividade do trabalho e da terra também apontam para o aumento da produtividade desses fatores (Hoffmann e Jamas, 1990, Carvalho, 1993, Guerreiro, 1995).

As políticas setoriais, as quais foram responsáveis pela rápida tecnificação da agropecuária, tiveram impactos diferenciados nas diversas regiões brasileiras. Há uma vasta literatura que trata desses efeitos diferenciados das políticas setoriais no processo de modernização da agropecuária. ${ }^{1} \mathrm{O}$ sistema de crédito oficial, uma das principais políticas implementadas no país para dinamizar e modernizar a agropecuária, beneficiou algumas atividades e regiões mais intensamente do que outras. Por exemplo, as Regiões Sudeste, Sul e Centro-Oeste apresentaram acelerado processo de tecnificação; em contra partida, nos estados das Regiões Nordeste e Norte, os crescimentos da produção e da produtividade do setor agropecuário foram menos intensos.

O mercado de trabalho agrícola provavelmente reflete as diferenças regionais de crescimento da agropecuária, mesmo considerando que a mão-de-obra empregada nessa atividade seja pouco qualificada e que exista elevada homogeneidade nesta mão-de-obra.

Existem diversos trabalhos econométricos tentando explicar os fatores determinantes dos salários agrícolas no Brasil. Esses trabalhos se distinguem pela metodologia utilizada (usando método dos mínimos quadrados ordinários ou equações

\footnotetext{
${ }^{1}$ Staduto e Freitas (2001) fazem uma revisão sobre o tema.
} 
simultâneas), pelo período de tempo considerado na análise e pela abrangência territorial considerada (se referindo a estados, segmentos da agropecuária ou a todo o Brasil). Entre esses trabalhos se destacam: Saylor (1974), Gasques (1975, 1981), Cunha e Maia (1984), Bacha (1991), Istake (1999), Staduto et alii (2002a).

O presente artigo não se preocupa em analisar os determinantes dos salários agrícolas, mas sim em avaliar se esses salários apresentam arbitragem ${ }^{2}$ no âmbito nacional ou regional. Este tipo de análise só foi realizada, em parte, pelo trabalho de Staduto et alii (2002b).

O trabalho de Staduto et alii (2002b) analisou as tendências ao longo do tempo das diferenças de salários entre os trabalhadores permanentes do Brasil. O presente trabalho amplia essa análise, adicionando a análise referente ao diferencial de salários de trabalhadores temporários e comparando os resultados dessas duas categorias de trabalhadores.

O presente artigo está organizado em quatro seções, incluindo esta introdução. Na segunda seção são apresentados a fundamentação teórica, os procedimentos econométricos e a fonte dos dados utilizados para tratar do comportamento de longo prazo do diferencial de salários na agropecuária. Na terceira seção são analisados os resultados dos modelos estimados; e na última seção são apresentadas as conclusões do artigo.

\section{Arcabouços Teórico e Metodológico}

Esta seção discute a abordagem teórica que fundamenta a existência de um processo de arbitragem de salários na agropecuária (item 2.1). Em seguida, os procedimentos econométricos para avaliação desse processo são apresentados (item 2.2), seguidos da análise dos dados utilizados (item 2.3).

\subsection{Abordagem teórica}

Este estudo baseou-se na abordagem da lei do preço único, a qual preconiza que caso os mercados sejam suficientemente integrados o preço será o mesmo. Conforme Arbache (2000), o objetivo mais comum nos estudos de diferencial de salários é testar a hipótese da lei do preço único para a determinação dos salários

\footnotetext{
${ }^{2}$ Arbitragem é aqui entendida como sendo o processo que leva à definição de uma diferença estável entre os salários. Este processo ocorre devido à mobilidade efetiva ou potencial dos trabalhadores. Observe que apenas a ameaça de deslocamento dos trabalhadores permanentes de áreas de baixos salários para as de maior salários (a mobilidade potencial) é suficiente para gerar a arbitragem dos salários. 
em mercados competitivos. Várias pressuposições são normalmente feitas nesse contexto, tais como: homogeneidade, plena mobilidade (intersetorial e locacional) dos fatores de produção e informação perfeita dos agentes sobre o mercado. Estas três pressuposições são fundamentais para examinar as relações de longo prazo dos salários dos trabalhadores agrícolas em termos inter e intra-regionais, uma vez que aquelas pressuposições justificam a existência de arbitragem, que propicia a transmissão de preço (ou de salário, que é o preço pelo uso do fator trabalho) entre diferentes localidades, naturalmente com maior probabilidade de ocorrer no contexto de longo prazo. Caso ocorra essa relação, pode-se inferir que os mercados são integrados.

A lei do preço único pode ser adaptada à análise do mercado de trabalho agrícola. Espera-se que o diferencial de salários tenda a um nível estável para certas categorias relativamente homogêneas de trabalhadores entre si (como os trabalhadores permanentes versus os trabalhadores temporários) e em regiões onde haja maior mobilidade e interação entre esses trabalhadores. Não se espera, no entanto, que o salário de uma mesma categoria de trabalhador em áreas distintas seja o mesmo (ou seja, idênticos), pois há características estruturais diferentes da agropecuária de uma região para outra.

Os trabalhadores agrícolas podem ser enquadrados como mão-de-obra nãoqualificada. Pode-se fazer tal inferência considerando que a força de trabalho agrícola, no seu conjunto, apresenta baixo nível de escolaridade e especialização. Além disso, deve-se levar em consideração que os postos de trabalho exigem, no seu conjunto, baixa especificidade e têm rotinas laborais pouco complexas. É conhecido que os trabalhadores permanentes apresentam maior especialização do que os trabalhadores temporários. Com o crescimento da importância dos trabalhadores permanentes, espera-se que haja forte tendência de crescimento dos postos qualificados de trabalho na agropecuária, pois a sua expansão está fortemente associada a uma nova fase tecnológica do setor agropecuário a partir dos anos 90. No entanto, na média, o setor agropecuário pode ser considerado como usando trabalho pouco qualificado. Esta situação, de fato, revela-se com maior nitidez quando ela é comparada aos trabalhadores engajados em outras atividades econômicas. No caso, pode-se atribuir aos trabalhadores agrícolas, temporários e permanentes, algumas características muito próximas de um fator de produção homogêneo.

Caso a mobilidade da mão-de-obra fosse grande entre setores de atividade econômica, haveria um salário arbitrado entre os mercados de trabalho. No entanto, tratando-se de trabalhadores agrícolas, mais especificamente de mão-deobra pouco qualificada, podem existir barreiras à mobilidade intersetorial desse 
fator de produção. Neste caso, a mobilidade intersetorial ficaria restrita aos ramos de atividade que tenham postos de trabalhos que exijam pouca complexidade laboral.

Segundo Camarano e Abramovay (1998), desde 1950, a cada dez anos, um em cada três brasileiros vivendo no meio rural opta pela migração e, inclusive, nos anos 90 não se arrefeceu esta tendência. Neste sentido, Alves et alii (1999) afirmam que nesta última década parte do crescimento da população das cidades brasileira ainda é resultado do êxodo rural.

Nesta rápida evasão do campo em direção às cidades, a literatura cita freqüentemente a construção civil como sendo o principal setor da economia na absorção de trabalhadores agrícolas. No entanto, esta mobilidade intersetorial é mais factível para os trabalhadores temporários, porque os permanentes recebem, normalmente, salários indiretos (sob as formas de moradia, água, luz, parte da produção, produção para autoconsumo, entre outros benefícios) que têm como efeito a redução da sua mobilidade.

Outras atividades não-agrícolas fazem parte das possibilidades intersetoriais no próprio espaço rural. Silva (1999) evidenciou que a importância destas atividades cresceu nos anos 90. A renda dos indivíduos que se dedicam a atividades agrícolas e não-agrícolas são maiores em relação àqueles que se dedicam exclusivamente a atividades agrícolas.

A mobilidade no próprio setor agropecuário, associada à mudança de região, fica reservada para uma menor parcela da população ocupada na agropecuária. Nesta circunstância, haveria uma mobilidade locacional que poderia se dar de forma inter e intra-regional. A mobilidade da mão-de-obra deve ser entendida de forma mais correta, denominando-a de deslocamento de mão-de-obra, visto que quando o deslocamento dos trabalhadores ocorrer por meio da migração há mudança de residência da unidade familiar, em direção ao campo ou à cidade. Nesta situação é mais factível que esta mão-de-obra quando migra para outra região no sentido rural-rural esteja influenciando preferencialmente o mercado de trabalho agrícola do segmento dos trabalhadores permanentes. Por outro lado, o deslocamento da mão-de-obra por meio da mobilidade do trabalhador em períodos sazonais - ou seja, os indivíduos que deixam as suas famílias em um determinado período do ano para trabalhar em outras regiões - está associada aos trabalhadores temporários. Outro pressuposto considerado na lei do preço único é o pleno conhecimento do mercado de trabalho por meio do fluxo de informações. Mesmo que a informação sobre a faixa salarial dos trabalhadores agrícolas seja conhecida pelos agentes ofertantes e demandantes, ou seja, há informações perfeitas sobre o mercado de fatores, isto não garante, necessariamente, que os salários sejam rela- 
cionados. Isto porque outras condições inerentes à oferta e à demanda de trabalho devem ser consideradas, como os aspectos estruturais que afetam o funcionamento do mercado de trabalho de cada região. Isto se expressa em diferentes salários médios recebidos pelos trabalhadores agrícolas. Neste caso, os mercados teriam um baixíssimo grau de integração.

No entanto, diferentes salários médios não implicam que os mercados não se relacionam. É possível que o diferencial de salários se mantenha ao longo dos anos, e isto reflita em um elevado grau de integração.

As diferenças dos salários médios agrícolas podem ser analisadas e qualificadas, segundo o grau de integração dos mercados, os quais se classificam em integrados ou não integrados. Em ambos os casos, as características regionais estariam envolvidas, e elas podem interferir no grau de integração entre os mercados de trabalho. Entre essas variáveis, tem-se: a estrutura fundiária, a produtividade do trabalho, organizações de trabalhadores e patronais, custo de vida médio, por exemplo.

\subsection{Procedimentos econométricos}

Os procedimentos econométricos utilizados para analisar o grau de integração dos mercados agrícolas por intermédio dos salários agrícolas dos trabalhadores temporários e permanentes fundamentam-se em testes de co-integração. Como só é procedente testar co-integração no caso de séries não estacionárias (ou seja, séries integradas), primeiramente realizam-se os testes de raiz unitária, utilizando a metodologia de Dickey-Fuller Aumentado (Fuller, 1976, Dickey e Fuller, 1979, 1981) para verificar a ordem de integração das variáveis consideradas (número de raízes unitárias). A seguinte formulação geral é utilizada nos testes:

$$
\Delta y_{t}=\alpha+\beta T+\eta y_{t-1}+\sum_{i=1}^{p-1} \phi_{i} \Delta y_{t-1}+e_{t}
$$

na qual

$y_{t}$ é a variável analisada (o salário real médio semestral);

$\Delta$ é o operador diferença, tal que $\Delta y_{t}=y_{t}-y_{t-1}$;

$\alpha$ é o intercepto;

$T$ é a variável tendência (variável determinista);

$e_{t}$ é o termo estocástico "ruído branco"; e

$p$ é a ordem do processo auto-regressivo que descreve o comportamento da série.

O procedimento proposto por Enders (1995) foi adotado com a finalidade de auxiliar na definição correta do modelo a ser utilizado no teste - incluindo ou não a constante e a tendência determinista. O número de defasagens do modelo, as 
quais têm a finalidade de eliminar a autocorrelação dos resíduos, foi determinado de acordo com os critérios de Akaike e Schwarz.

As estatísticas utilizadas são as $\tau_{\beta \tau}$ e $\tau_{\alpha \mu}$ que avaliam, respectivamente, a significância dos coeficientes da variável tendência $(\beta)$ do modelo que inclui essa variável e da constante no modelo em que a tendência é excluída; e as estatísticas $\tau_{\tau}, \tau_{\mu}$ e $\tau$, as quais correspondem, respectivamente, aos coeficientes da variável defasada $(\eta)$ dos modelos: com constante e tendência, apenas com constante, e sem constante e tendência.

Se o teste aponta para a existência de raiz unitária, ele é repetido utilizando um modelo ajustado com a série com uma diferença a mais, processo este que é repetido até que se verifique a estacionariedade da série. A ordem de integração é dada pelo número de vezes que a série deve ser diferenciada para se tornar estacionária.

Os valores críticos dos testes de raiz unitária são apresentados em Fuller (1976) e Dickey e Fuller (1981). Uma descrição detalhada da metodologia é apresentada em Harvey (1990) e Hamilton (1994).

Cumpre lembrar que o teste de raiz unitária de Dickey e Fuller é recomendado para casos em que se suspeita que a série é integrada de ordem um (tem apenas uma raiz unitária), sendo o teste de Dickey e Pantula indicado para séries em que se suspeita da existência de mais de uma raiz unitária (Enders, 1995). Como as séries de salários utilizadas nesse estudo são expressas em valores reais, é bastante plausível pressupor que elas possam ter apenas uma raiz unitária. Dessa forma, o teste de Dickey e Fuller aumentado pode ser utilizado. Além do mais, a primeira fase do teste de Dickey e Pantula - aplicado nos casos em que se suspeita da existência de duas raízes unitárias no processo gerador da série temporal - é uma aproximação da fase dois do teste de Dickey e Fuller aplicado a processos em que se identificou raiz unitária na primeira fase (Enders, 1995).

Se as variáveis são integradas de primeira ordem, o próximo passo é testar a existência de co-integração entre elas, o que pode ser feito utilizando o procedimento proposto por Johansen (1988), que se baseia na seguinte versão reparametrizada de um modelo $\operatorname{VAR}(\mathrm{p})$.

$$
\Delta y_{t}=\Gamma_{1} \Delta y_{t-1}+\ldots+\Gamma_{p-1} \Delta y_{t-p+1}+\Pi y_{t-1}+\mu+\epsilon_{t}
$$


onde:

$y_{t}$ é um vetor com $k$ variáveis;

$p$ é a ordem do processo auto-regressivo;

$\epsilon_{t} \sim N(0, \Sigma) ; \mathrm{e}$

$E\left(e_{t} e_{s}^{\prime}\right)=0$ para qualquer $t$ diferente de $s$.

Considerando que $r$ seja o posto da matriz $\Pi$, então $\Pi$ tem $r$ autovalores diferentes de zero e, portanto, $r$ vetores de co-integração. Se $r=k$ então $y_{t}$ é estacionário; se $r=0$ então $\Delta y_{t}$ é estacionário; e, se $0<r<n$ existem matrizes $\alpha$ e $\beta$ de dimensão $k \times r$ tais que $\Pi=\alpha \beta^{\prime}$ e o vetor $\beta^{\prime}$ é estacionário. Johansen e Juselius (1990) propõem dois testes para identificar o número de vetores de cointegração: teste do traço e do $\lambda_{\max }$. Os critérios AIC (AKAIKE Information Criterion) e SC (SCHWARZ Criterion), num contexto multi-equacional, podem ser usados para a determinação do valor de $p$.

\subsection{Fonte dos Dados}

Os dados sobre salários dos trabalhadores permanentes foram obtidos junto à Fundação Getulio Vargas do Rio de Janeiro. Esses dados têm freqüência semestral e referem-se ao período de 1966 até o primeiro semestre de 2002. Os valores nominais foram transformados em valores deflacionados utilizando o IGP-DI como deflator. No total, 73 observações para cada estado em análise foram consideradas, apesar de que o número utilizado nos modelos foi menor devido às defasagens definidas.

As relações inter-regionais de longo prazo das médias salariais dos trabalhadores agrícolas permanentes foram analisadas considerando as regiões Nordeste, Centro-Oeste, Sudeste e Sul. No tocante às relações intra-regionais, foram considerados no estudo sete estados pertencentes à região Nordeste (Maranhão, Ceará, Rio Grande do Norte, Paraíba, Pernambuco, Sergipe e Bahia), quatro estados da região Sudeste (Minas Gerais, Espírito Santo, Rio de Janeiro e São Paulo), três estados da região Sul (Paraná, Santa Catarina e Rio Grande do Sul) e três estados da região Centro-Oeste (Mato Grosso do Sul, Mato Grosso e Goiás). Os demais estados do território nacional e a Região Norte não foram incluídos na análise em razão da ausência de informações para todo o período de abrangência do estudo. 
Os salários reais dos trabalhadores permanentes e temporários apresentaram flutuações no período em análise, as quais não são homogêneas, mas permitem definir as seguintes tendências: eles aumentaram de 1966 até meados da década de 70 em alguns estados e até final da década de 70 em outros estados; eles caíram durante a década de 80 , sendo que em alguns estados eles ainda continuaram a cair nos três primeiros anos da década de 90 , e em outros estados os salários rurais reais permaneceram estáveis, em um nível baixo, no começo da década de 90; os salários reais aumentaram a partir de 1994.

Além dessas tendências, em 1984 houve a unificação dos salários mínimos regionais, o que levou à maior estabilidade do diferencial de salários entre as categorias de trabalhadores entre as regiões do Brasil.

Diante dessas tendências e comportamentos, os modelos das equações (1) e (2) foram estimados em três situações: (a) incluindo uma variável dummy a partir de 1984, quando houve a unificação dos salários mínimos regionais; (b) incluindo uma variável dummy a partir de 1994, quando houve a criação do Plano Real; (c) não incluindo variáveis dummies. ${ }^{3}$

Grande parte das regressões do grupo (a), mas não todas, apresentaram significância estatística para a variável dummy. No entanto, resultados similares ocorreram quando a variável dummy foi iniciada em 1982 ou em 1983. Além disso, a inclusão dessa variável dummy não mudou significativamente os resultados obtidos no grupo (c) de regressões, para os casos onde não se verificaram relações de longo prazo entre os salários.

As variáveis dummies para o grupo (b), para captar os efeitos do Plano Real, não foram estatisticamente significativas.

Os resultados obtidos nas regressões do grupo (c) não são significativamente diferentes das do grupo (a) nos casos onde a variável dummy foi significativa estatisticamente. Devido a isso, apresentam-se a seguir os resultados das estimativas do grupo (c), ou seja, sem incluir variáveis dummies na análise.

\footnotetext{
${ }^{3}$ Modelos com variáveis dummies para as tendências observadas de 1966 até o final da década de 70 e de 1980 até os três primeiros anos da década de 90 não foram estimados, pois os comportamentos dos salários reais variaram significativamente entre os estados, impedindo o uso de um critério único para definição das dummies. 


\section{Resultados Empíricos}

A seguir, os resultados dos modelos comentados no item 2 são avaliados para os casos dos trabalhadores permanentes (item 3.1) e dos trabalhadores temporários (item 3.2). O núnero utilizado de defasagens nos modelos, tanto no caso dos testes de raiz unitária como no de co-integração, foi definido de acordo com os critérios de AKAIKE e SCHWARZ (para versão uniequacional e multiequacional, respectivamente). Quando esses critérios indicavam ordens diferentes para o processo auto-regressivo a ser considerado, buscava-se especificar o modelo fundamentandose no princípio de parcimônia, respaudando-se, no entanto, em resultados de testes de correlação e normalidade de resíduos. Nos casos em que o teste de normalidade apresentava-se significativo, o que é comum ocorrer em dados econômicos brasileiros (Lopes, 1995), utilizava-se como referência para a análise de co-integração o modelo que apresentava o maior nível de significância.

\subsection{Análise dos salários dos trabalhadores permanentes}

Os resultados dos testes de raiz unitária (equação 1) apontam que todas as séries dos salários dos trabalhadores permanentes dos estados considerados na análise (Maranhão, Ceará, Rio Grande do Norte, Paraíba, Pernambuco, Sergipe, Bahia, Minas Gerais, Espírito Santo, Rio de Janeiro, São Paulo, Paraná, Santa Catarina, Rio Grande Sul, Mato Grosso do Sul, Mato Grosso e Goiás) são não estacionárias. Considerando as séries nas diferenças de primeira ordem e realizando novos testes de raiz unitária, constata-se que essas diferenças são estacionárias (veja os resultados na última coluna da tabela 1). Combinando os resultados obtidos no ajustamento dos dois modelos apresentados abaixo da tabela 1, pode-se inferir que as séries mencionadas são integradas de ordem um, ou seja, $I(1)$. Utilizando essa mesma sistemática para análise, observa-se que as séries dos salários médios vigentes nas regiões Nordeste, Sudeste, Sul e Centro-Oeste também apresentaram uma raiz unitária (tabela 2). 
Tabela 1

Resultados dos testes de raiz unitária de Dickey-Fuller para os salários dos trabalhadores agrícola permanentes nos estados selecionados

\begin{tabular}{cccccccc}
\hline & & \multicolumn{5}{c}{ Modelo $1^{*}$} & Modelo $2^{* *}$ \\
\cline { 2 - 7 } Estado & Valor de $p$ & $\tau_{\beta \tau}$ & $\tau_{\tau}$ & $\tau_{\alpha \mu}$ & $\tau_{\mu}$ & $\tau$ & $\tau$ \\
\hline MA & 2 & $-1,46$ & $-2,14$ & 1,55 & $-1,57$ & $-0,29$ & $-13,68^{a}$ \\
CE & 2 & $-1,01$ & $-2,01$ & 1,79 & $-1,78$ & 0,02 & $-13,52^{a}$ \\
RN & 2 & $-0,73$ & $-1,98$ & 1,84 & $-1,84$ & $-0,18$ & $-13,28^{a}$ \\
PB & 1 & $-1,02$ & $-2,57$ & 2,39 & $-2,39$ & 0,01 & $-10,47^{a}$ \\
PE & 2 & $-1,41$ & $-1,93$ & 1,79 & $-1,79$ & 0,09 & $-12,54^{a}$ \\
SE & 2 & $-1,29$ & $-2,30$ & 1,89 & $-1,91$ & $-0,29$ & $-11,19^{a}$ \\
BA & 8 & $-2,01$ & $-2,28$ & 1,21 & $-1,23$ & $-0,31$ & $-2,33^{a}$ \\
MG & 4 & $-1,87$ & $-1,96$ & 1,17 & $-1,17$ & $-0,08$ & $-4,60^{a}$ \\
ES & 5 & $-2,13$ & $-1,91$ & 1,02 & $-1,02$ & $-0,09$ & $-4,35^{a}$ \\
RJ & 5 & $-1,85$ & $-1,70$ & 0,75 & $-0,76$ & $-0,29$ & $-4,71^{a}$ \\
SP & 9 & $-1,56$ & $-2,27$ & 1,62 & $-1,64$ & $-0,57$ & $-2,30^{a}$ \\
PR & 5 & $-2,18$ & $-2,05$ & 0,68 & $-0,69$ & $-0,34$ & $-4,42^{a}$ \\
SC & 2 & $-1,79$ & $-2,17$ & 1,31 & $-1,32$ & $-0,43$ & $-13,27^{a}$ \\
RS & 2 & $-1,52$ & $-1,90$ & 1,13 & $-1,15$ & $-0,47$ & $-13,49^{a}$ \\
MS & 2 & $-1,89$ & $-2,19$ & 1,31 & $-1,32$ & $-0,17$ & $-15,56^{a}$ \\
MT & 2 & $-1,14$ & $-2,13$ & 1,78 & $-1,79$ & $-0,30$ & $-12,49^{a}$ \\
GO & 2 & $-1,69$ & $-2,59$ & 2,05 & $-2,04$ & 0,09 & $-13,32^{a}$ \\
\hline Fonyyyyyy
\end{tabular}

Fonte: Dados da Pesquisa.

a significativo ao nível de 0,05 de probabilidade.

* Modelo $1-\Delta y_{t}=\alpha+\beta T+\eta y_{t-1}+\sum_{i=1}^{p-1} \phi_{i} \Delta y_{t-1}+e_{t}$,

nas versões (a) com constante e tendência, (b) sem tendência,

e (c) sem tendência e sem constante.

** Modelo $2-\Delta \Delta y_{t}=\eta \Delta y_{t-1}+\sum_{i=1}^{p-2} \phi_{i} \Delta \Delta y_{t-1}+e_{t}$,

definido depois de constatada a não existência de termos deterministas.

Tabela 2

Resultados dos testes de raiz unitária de Dickey-Fuller para os salários dos trabalhadores agrícolas permanentes nas regiões selecionadas

\begin{tabular}{cccccccc}
\hline & & \multicolumn{3}{c}{ Modelo $1^{*}$} & \multicolumn{3}{c}{ Modelo $2^{* *}$} \\
\cline { 3 - 7 } Regiões & Valor de $p$ & $\tau_{\beta \tau}$ & $\tau_{\tau}$ & $\tau_{\alpha \mu}$ & $\tau_{\mu}$ & $\tau$ & $\tau$ \\
\hline Nordeste & 4 & $-1,71$ & $-1,66$ & 1,00 & $-1,01$ & $-0,13$ & $-5,56^{a}$ \\
Sudeste & 2 & $-2,03$ & $-2,40$ & 1,56 & $-1,55$ & 0,04 & $-13,63^{a}$ \\
Sul & 2 & $-1,69$ & $-1,81$ & 0,87 & $-0,89$ & $-0,49$ & $-14,59^{a}$ \\
Centro-Oeste & 2 & $-1,70$ & $-2,29$ & 1,65 & $-1,65$ & $-0,02$ & $-14,14^{a}$ \\
\hline
\end{tabular}

Fonte: Dados da Pesquisa.

a significativo ao nível de 0,05 de probabilidade.

* Modelo $1-\Delta y_{t}=\alpha+\beta T+\eta y_{t-1}+\sum_{i=1}^{p-1} \phi_{i} \Delta y_{t-1}+e_{t}$,

nas versões (a) com constante e tendência, (b) sem tendência,

e (c) sem tendência e sem constante.

** Modelo $2-\Delta \Delta y_{t}=\eta \Delta y_{t-1}+\sum_{i=1}^{p-2} \phi_{i} \Delta \Delta y_{t-1}+e_{t}$,

definido depois de constatada a não existência de termos deterministas.

Como as séries temporais analisadas são integradas de mesma ordem (esta- 
cionárias nas diferenças de primeira ordem) realizam-se os testes de co-integração para analisar a existência de relações de longo prazo. Os resultados da estimativa do modelo multivariado de Johansen (1988), representado na equação (2) da seção 2, permitem concluir que não existem relações de equilíbrio de longo prazo entre os salários dos trabalhadores permanentes das regiões Nordeste, Sudeste, Sul e Centro-Oeste, pois os testes Traço e $\lambda_{\max }$ foram não significativos (tabela 3 ). Considerando estes resultados pode-se inferir que os mercados são pouco integrados em termos inter-regionais.

Tabela 3

Resultados dos testes de co-integracão de Johansen dos salários dos trabalhadores agrícolas permanentes - Regiões Nordeste, Sudeste, Sul e Centro-Oeste

\begin{tabular}{cccc}
\hline Hipótese Nula & Hipótese Alternativa & Traço & $\lambda_{\max }$ \\
\hline$r \leq 3$ & $\mathrm{r}=4$ & $3,96^{N S}$ & $3,96^{N S}$ \\
$r \leq 2$ & $\mathrm{r}=3$ & $12,25^{N S}$ & $8,29^{N S}$ \\
$r \leq 1$ & $\mathrm{r}=2$ & $28,74^{N S}$ & $16,49^{N S}$ \\
$r=0$ & $\mathrm{r}=1$ & $50,96^{N S}$ & $22,22^{N S}$ \\
\hline Fonte: Dados da Pesquisa. & \\
Nota: a significativo ao nível de 0,05 de probabilidade e \\
NS é não significativo. Os valores críticos para os testes Traço e \\
$\lambda_{\text {max }}$ estão em Osterwald-Lenum (1992). O modelo estimado \\
foi com constante restrita, e ajustado com duas defasagens.
\end{tabular}

Visando uma maior robustez dos resultados obtidos, que sinalizam ausência de relações de equilíbrio de longo prazo entre os salários dos trabalhadores agrícolas permanentes das diferentes regiões consideradas no estudo, foram feitos testes de co-integração combinando as regiões duas a duas. Os resultados apresentados na tabela 4 corroboram os obtidos no teste de co-integração dos salários regionais tratados conjuntamente, com exceção do caso do Sul/Centro-Oeste e Sudeste/CentroOeste. Para eles, os resultados dos testes de co-integração alternativos (traço e $\left.\lambda_{\max }\right)$ não possibilitam uma análise conclusiva a respeito das relações de longo prazo, uma vez que o teste do $\lambda \max$ aponta para a existência de co-integração e o do traço não. Isso se deve, provavelmente, ao fato de existir uma relação de longo prazo fraca entre os salários dessas regiões, o que leva a um problema de indefinição da relação. 
Tabela 4

Resultados dos testes de co-integracão de Johansen dos salários dos trabalhadores agrícolas permanentes - Regiões Nordeste (NE), Sudeste (SE), Sul (S) e Centro-Oeste (CO)

\begin{tabular}{ccccc}
\hline Regiões Testas & Hipótese Nula & Hipótese Alternativa & Traço & $\lambda_{\max }$ \\
\hline NE e SE & $r \leq 1$ & $r=2$ & $4,17^{N S}$ & $4,17^{N S}$ \\
& $r=0$ & $r=1$ & $11,76^{N S}$ & $7,58^{N S}$ \\
NE e S & $r \leq 1$ & $r=2$ & $3,91^{N S}$ & $3,91^{N S}$ \\
& $r=0$ & $r=1$ & $13,02^{N S}$ & $9,11^{N S}$ \\
SE e S & $r \leq 1$ & $r=2$ & $1,75^{N S}$ & $1,75^{N S}$ \\
& $r=0$ & $r=1$ & $16,53^{N S}$ & $14,78^{N S}$ \\
SE e CO & $r \leq 1$ & $r=2$ & $2,44^{N S}$ & $2,44^{N S}$ \\
& $r=0$ & $r=1$ & $19,63^{N S}$ & $17,19^{a}$ \\
NE e CO & $r \leq 1$ & $r=2$ & $2,57^{N S}$ & $2,57^{N S}$ \\
& $r=0$ & $r=1$ & $12,22^{N S}$ & $9,65^{N S}$ \\
S e CO & $r \leq 1$ & $r=2$ & $1,62^{N S}$ & $1,62^{N S}$ \\
& $r=0$ & $r=1$ & $18,45^{N S}$ & $16,82^{a}$ \\
\hline
\end{tabular}

Fonte: Dados da Pesquisa.

Nota: ${ }^{a}$ significativo ao nível de 0,05 de probabilidade e

NS é não significativo. Os valores críticos para os testes Traço e

$\lambda_{\max }$ estão em Osterwald-Lenum (1992). Os modelos

foram estimados com constante restrita, e ajustados com duas defasagens, exceto no caso do Nordeste e Sul que foi ajustado com três defasagens.

Analisando as migrações nas décadas de 60 e 70, verifica-se que a região Nordeste foi uma exportadora de mão-de-obra, especialmente de mão-de-obra nãoqualificada, sendo a região Sudeste o principal destino dessa força de trabalho. Já nas décadas de 80 e 90, o fluxo migratório foi, de forma geral, de caráter intraregional, ou seja, a população rural movimentava-se dentro da própria região ou estado. Estes fluxos migratórios ocorreram, fundamentalmente, no sentido ruralurbano. Mesmo no caso do fluxo verificado entre as regiões Nordeste e Sudeste, com forte migração de mão-de-obra da primeira para a segunda região, observouse pouca influência da migração na arbitragem salarial dos trabalhadores agrícolas permanentes, principalmente pelo fato dos deslocamentos dos trabalhadores terem caráter intersetorial.

Particularmente no caso do fluxo migratório da região Sul para ao CentroOeste, cujo sentido foi rural-rural, o qual ocorreu de forma mais intensa na década de 70, poderia se esperar uma arbitragem expressiva dos salários. No entanto, na década de 80 esse fluxo migratório foi menos intenso. Esse fato pode justificar a fraca relação de longo prazo observada entre os salários dos trabalhadores agrícolas permanentes dessas duas regiões.

Outro fator que pode ter contribuído para que as relações inter-regionais dos salários dos trabalhadores agrícolas permanentes fossem pouco expressivas foi a tecnificação do setor agropecuário, a qual aumentou a produtividade do trabalho de forma diferenciada entre os estados. Espera-se que o aumento da produtividade 
média do trabalho tenha maior impacto no caso dos trabalhadores permanentes em relação aos temporários. Este fenômeno ocorreu praticamente em todo o país e pode ter influenciado a arbitragem dos salários.

A institucionalização do salário mínimo para o mercado de trabalho agrícola poderia ter gerado um grande grau de associação entre ele e os salários dos trabalhadores agrícolas permanentes. Isto, por sua vez, poderia ter-se refletido em uma relação de longo prazo entre os salários dos trabalhadores permanentes das diversas regiões. Dois motivos, no entanto, podem justificar a não constatação de relação de longo prazo significativa entre as médias salariais regionais dos trabalhadores agrícolas permanentes por influência do salário mínimo. Primeiramente, deve-se considerar que a institucionalização do salário mínimo não garante que o mesmo seja pago em sua integridade, principalmente nas zonas rurais, nas quais os sindicatos são pouco atuantes em relação aos urbanos; e, além disso, as instituições jurídicas que poderiam impor a aplicação da lei geralmente atuam de forma mais precária nas áreas rurais. O segundo motivo está relacionado ao fato do salário mínimo, até maio de 1984, ter um valor diferente para cada unidade da federação e somente a partir dessa data ter sido unificado. Considerando este argumento, caso os salários estivessem associados aos salários mínimos vigentes em cada estado, deveria haver níveis salariais diferentes em cada um deles.

Constata-se que a determinação dos salários dos trabalhadores permanentes nas diversas regiões se deu sob condições locais particulares. As principais particularidades estão associadas à produtividade do trabalho, ao nível médio da renda da população rural, à dimensão da oferta, ao custo de vida e ao salário mínimo. Verifica-se que - mesmo nas regiões de elevada produtividade do trabalho (como são os casos do Centro-Oeste, Sudeste e Sul) - não houve expressiva relação de longo prazo entre os salários no período analisado (1966 a 2002). Além da restrita mobilidade do trabalhador permanente entre regiões no setor agropecuário, devese considerar a estrutura fundiária e a composição das atividades agropecuárias dessas regiões como fatores que contribuíram para ausência de relação entre os salários dos trabalhadores permanentes no período analisado.

Os resultados dos testes de Johansen demonstram que as séries de salários dos trabalhadores agrícolas permanentes dos estados dentro de cada região são co-integradas (tabelas 5, 6, 7 e 8), evidenciando a existência de relações de longo prazo no período analisado (1966 a 2002). A mobilidade, efetiva ou potencial, da mão-de-obra dentro de cada região poderia ter influenciado nesse mecanismo de transmissão. A literatura não é clara quanto à possibilidade de ter ocorrido efetivamente, pelo menos em grande parte do período analisado, migração intraregional de tal magnitude que pudesse refletir no mercado de trabalho e estabelecer 
algum grau de relacionamento entre os salários no longo prazo.

Tabela 5

Resultados dos testes de co-integracão de Johansen dos salários dos trabalhadores agrícolas permanentes - Estados da Região Nordeste (Maranhão, Ceará, Rio Grande do Norte, Paraíba, Pernambuco, Sergipe e Bahia)

\begin{tabular}{cccc}
\hline Hipótese Nula & Hipótese Alternativa & Traço & \multicolumn{1}{c}{$\lambda_{\max }$} \\
\hline$r \leq 6$ & $r=7$ & $3,44^{N S}$ & $3,44^{N S}$ \\
$r \leq 5$ & $r=6$ & $12,03^{N S}$ & $8,59^{N S}$ \\
$r \leq 4$ & $r=5$ & $21,38^{N S}$ & $9,35^{N S}$ \\
$r \leq 3$ & $r=4$ & $33,83^{N S}$ & $12,45^{N S}$ \\
$r \leq 2$ & $r=3$ & $58,36^{N S}$ & $24,53^{N S}$ \\
$r \leq 1$ & $r=2$ & $98,34^{N S}$ & $39,98^{N S}$ \\
$r=0$ & $r=1$ & $158,45^{a}$ & $60,11^{a}$ \\
\hline
\end{tabular}

Fonte: Dados da Pesquisa.

Nota: ${ }^{a}$ significativo ao nível de 0,05 de probabilidade e

NS é não significativo. Os valores críticos para os testes Traço e

$\lambda_{\max }$ estão em Osterwald-Lenum (1992). O modelo estimado

foi com constante restrita, e ajustados com duas defasagens.

\section{Tabela 6}

Resultados dos testes de co-integracão de Johansen dos salários dos trabalhadores agrícolas permanentes - Estados da Região Sudeste (Minas Gerais, Espirito Santo, Rio de Janeiro e São Paulo)

\begin{tabular}{cccc}
\hline Hipótese Nula & Hipótese Alternativa & Traço & $\lambda_{\max }$ \\
\hline$r \leq 3$ & $r=4$ & $2,25^{N S}$ & $2,25^{N S}$ \\
$r \leq 2$ & $r=3$ & $12,48^{N S}$ & $10,23^{N S}$ \\
$r \leq 1$ & $r=2$ & $31,67^{N S}$ & $19,19^{N S}$ \\
$r=0$ & $r=1$ & $62,80^{a}$ & $31,13^{a}$ \\
\hline
\end{tabular}

Fonte: Dados da Pesquisa.

Nota: ${ }^{a}$ significativo ao nível de 0,05 de probabilidade e

NS é não significativo. Os valores críticos para os testes Traço e

$\lambda_{\max }$ estão em Osterwald-Lenum (1992). O modelo estimado

foi com constante restrita, e ajustados com duas defasagens.

\section{Tabela 7}

Resultados dos testes de co-integracão de Johansen dos salários dos trabalhadores agrícolas permanentes - Estados da Região Sul (Paraná, Santa Catarina e Rio Grande Sul)

\begin{tabular}{cccc}
\hline Hipótese Nula & Hipótese Alternativa & Traço & $\lambda_{\max }$ \\
\hline$r \leq 2$ & $r=3$ & $1,29^{N S}$ & $1,29^{N S}$ \\
$r \leq 1$ & $r=2$ & $14,73^{N S}$ & $13,44^{N S}$ \\
$r=0$ & $r=1$ & $35,99^{a}$ & $21,27^{N S}$ \\
\hline
\end{tabular}

Fonte: Dados da Pesquisa.

Nota: ${ }^{a}$ significativo ao nível de 0,05 de probabilidade e

NS é não significativo. Os valores críticos para os testes Traço e

$\lambda_{\max }$ estão em Osterwald-Lenum (1992). O modelo estimado

foi com constante restrita, e ajustados com duas defasagens. 
Tabela 8

Resultados dos testes de co-integracão de Johansen dos salários dos trabalhadores permanentes - Estados da Região Centro-Oeste (Mato Grosso do Sul, Mato Grosso e Goiás)

\begin{tabular}{cccc}
\hline Hipótese Nula & Hipótese Alternativa & Traço & $\lambda_{\max }$ \\
\hline$r \leq 2$ & $r=3$ & $2,08^{N S}$ & $2,08^{N S}$ \\
$r \leq 1$ & $r=2$ & $20,52^{a}$ & $18,44^{a}$ \\
$r=0$ & $r=1$ & $60,81^{a}$ & $40,29^{a}$ \\
\hline
\end{tabular}

Fonte: Dados da Pesquisa.

Nota: ${ }^{a}$ significativo ao nível de 0,05 de probabilidade e

NS é não significativo. Os valores críticos para os testes Traço e

$\lambda_{\max }$ estão em Osterwald-Lenum (1992). O modelo estimado

foi com constante restrita, e ajustados com duas defasagens.

Tratando-se de trabalhadores permanentes, no qual o custo econômico e nãoeconômico da mobilidade de um estado para outro pode ser bastante elevado quando comparado ao dos trabalhadores temporários, se poderia esperar mecanismos mais rígidos de transmissão de salários. No entanto, constatou-se a existência de equilíbrio de longo prazo dos salários daqueles trabalhadores para todas as regiões analisadas. Dentre as causas possíveis para explicar esse comportamento, pode-se citar o fato de que os trabalhadores permanentes devem ter um nível razoável de informação sobre o salário médio da região em que residem e reivindicam salários em torno dessa média. A maior homogeneidade existente dentro das regiões também pode ser apontada como causa da existência de relações de longo prazo entre os salários dos trabalhadores permanentes pertencentes a ela. Os fatores mencionados acima implicam mobilidade potencial dos trabalhadores permanentes no longo prazo.

O comportamento do salário mínimo deve ter influência na determinação dos salários dentro de cada localidade. Como foi examinado, o salário mínimo até 1984 era regionalizado, ou mais precisamente, era estabelecido um salário mínimo para cada estado. Desta forma, os salários mínimos nos estados de cada região eram muito próximos, refletindo o custo de vida local.

Além da possível contribuição do salário mínimo para a existência de relações entre os salários dos trabalhadores agrícolas permanentes dentro de cada região, deve-se ressaltar as semelhanças observadas entre os estados de uma mesma região como ponto fundamental para haver um equilíbrio de longo prazo entre os salários desses trabalhadores. Os aspectos regionais mais importantes devem ser a produtividade do trabalho, a estrutura fundiária, a composição da produção agropecuária, a renda média da população agrícola, o custo de vida, a efetividade das instituições jurídicas, a organização sindical, e outros. 
A figura 1 mostra, de modo geral, grande flutuação das diferenças entre as médias de salários até meados da década de 80. A partir desta data (coincidindo com o período de unificação dos salários mínimos regionais) há grandes diferenças entre as médias salariais das regiões, mas com menor flutuação dessas diferenças. Em outras palavras, as diferenças das médias salariais tendem a se estabilizar. A região do Nordeste apresenta a maior diferença salarial em relação a todas as demais regiões. Já as regiões Sudeste, Sul e Centro-Oeste, a partir da década de 90, apresentam bastante estabilidade nas diferenças salariais entre si, sendo que as flutuações reduziram-se na última metade desta década. Esta situação ocorre, muito provavelmente, em decorrência da estabilidade monetária propiciada pelo Plano Real.

Entre as variáveis que podem influenciar a formação dos salários agrícolas, espera-se que, no longo prazo, a produtividade do trabalho seja bastante influente em mercados com características próximas ao de concorrência perfeita. No entanto, segundo Staduto et alii (2002), a produtividade do trabalho teve pouca influência na determinação dos salários dessa categoria de mão-de-obra no período de 1971 a 1996 para as regiões mais e menos tecnificadas do Brasil. Esses autores também afirmaram que o salário mínimo foi a variável mais influente na determinação dos salários dos trabalhadores permanentes. O salário mínimo funcionou como um indexador. As particularidades regionais diferenciaram o nível salarial entre os trabalhadores permanentes.

Figura 1

Relação salarial dos trabalhadores permanentes entre as regiões brasileiras: nordeste $(\mathrm{NE})$, sudeste $(\mathrm{SE})$, sul $(\mathrm{S})$ e centro-oeste $(\mathrm{CO})$

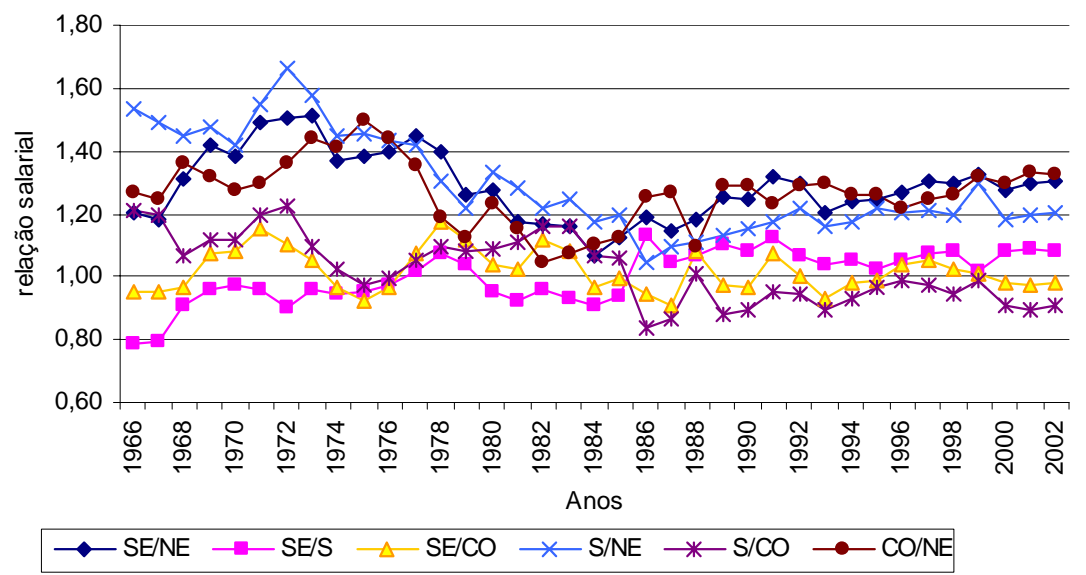




\subsection{Análise dos salários dos trabalhadores temporários}

Os resultados dos testes de raiz unitária (equação 1 da seção 2) apontam que todas as séries dos salários dos trabalhadores temporários dos estados considerados na análise (Maranhão, Ceará, Rio Grande do Norte, Paraíba, Pernambuco, Sergipe, Bahia, Minas Gerais, Espírito Santo, Rio de Janeiro, São Paulo, Paraná, Santa Catarina, Rio Grande Sul, Mato Grosso do Sul, Mato Grosso e Goiás) são não estacionárias. Considerando as séries nas diferenças de primeira ordem e realizando novos testes de raiz unitária, constata-se que essas diferenças de primeira ordem são estacionárias (veja a última coluna da tabela 9). As séries dos salários médios vigentes nas regiões Nordeste, Sudeste, Sul e Centro-Oeste também apresentaram uma raiz unitária, sendo a análise feita utilizando os dois modelos que aparecem abaixo da tabela 10 .

Tabela 9

Resultados dos testes de raiz unitária de Dickey-Fuller para os salários dos trabalhadores agrícolas temporários nos estados selecionados

\begin{tabular}{cccccccc}
\hline & & \multicolumn{3}{c}{ Modelo $1^{*}$} & Modelo $2^{* *}$ \\
\cline { 3 - 7 } Estado & Valor de $p$ & $\tau_{\beta \tau}$ & $\tau_{\tau}$ & $\tau_{\alpha \mu}$ & $\tau_{\mu}$ & $\tau$ & $\tau$ \\
\hline MA & 1 & $-1,43$ & $-2,58$ & 2,12 & $-2,19$ & $-0,53$ & $-10,03^{a}$ \\
CE & 1 & $-0,56$ & $-2,62$ & 2,53 & $-2,59$ & $-0,52$ & $-9,54^{a}$ \\
RN & 2 & $-0,39$ & $-1,97$ & $-1,95$ & $-1,98$ & $-0,28$ & $-11,41^{a}$ \\
PB & 2 & $-1,02$ & $-2,31$ & 2,10 & $-2,13$ & $-0,38$ & $-10,92^{a}$ \\
PE & 1 & $-0,98$ & $-3,04$ & 2,71 & $-2,76$ & $-0,49$ & $-10,37^{a}$ \\
SE & 1 & $-1,42$ & $-1,81$ & 1,53 & $-1,56$ & $-0,32$ & $-7,02^{a}$ \\
BA & 2 & $-1,53$ & $-2,11$ & 1,58 & $-1,62$ & $-0,36$ & $-11,24^{a}$ \\
MG & 1 & $-0,61$ & $-2,59$ & 2,61 & $-2,60$ & 0,05 & $-10,60^{a}$ \\
ES & 2 & $-0,65$ & $-2,20$ & 2,27 & $-2,26$ & $-0,08$ & $-10,85^{a}$ \\
RJ & 2 & 0,18 & $-2,25$ & 2,29 & $-2,27$ & 0,05 & $-10,60^{a}$ \\
SP & 3 & $-1,30$ & $-2,58$ & 2,51 & $-2,48$ & 0,07 & $-8,17^{a}$ \\
PR & 1 & $-1,08$ & $-2,73$ & 2,48 & $-2,50$ & $-0,32$ & $-10,58^{a}$ \\
SC & 5 & $-0,64$ & $-2,21$ & 2,32 & $-2,30$ & 0,16 & $-6,00^{a}$ \\
RS & 2 & $-0,32$ & $-2,25$ & 2,27 & -224 & 0,11 & $-11,31^{a}$ \\
MS & 2 & $-1,03$ & $-2,56$ & 2,37 & $-2,39$ & $-0,33$ & $-9,48^{a}$ \\
MT & 5 & $-1,09$ & $-2,27$ & 2,04 & $-2,05$ & $-0,22$ & $-5,53^{a}$ \\
GO & 5 & $-0,90$ & $-2,56$ & 2,54 & $-2,52$ & 0,01 & $-5,34^{a}$ \\
\hline Fonte: Danyyyyy
\end{tabular}

Fonte: Dados da Pesquisa.

${ }^{a}$ significativo ao nível de 0,05 de probabilidade.

* Modelo $1-\Delta y_{t}=\alpha+\beta T+\eta y_{t-1}+\sum_{i=1}^{p-1} \phi_{i} \Delta y_{t-1}+e_{t}$, nas versões (a) com constante e tendência, (b) sem tendência, e (c) sem tendência e sem constante.

** Modelo $2-\Delta \Delta y_{t}=\eta \Delta y_{t-1}+\sum_{i=1}^{p-2} \phi_{i} \Delta \Delta y_{t-1}+e_{t}$,

definido depois de constatada a não existência de termos deterministas. 
Tabela 10

Resultados dos testes de raiz unitária de Dickey-Fuller para os salários dos trabalhadores agrícolas temporários nas regiões selecionadas

\begin{tabular}{cccccccc}
\hline & & \multicolumn{3}{c}{ Modelo $1^{*}$} & \multicolumn{3}{c}{ Modelo $2^{* *}$} \\
\cline { 3 - 7 } Estado & Valor de $p$ & $\tau_{\beta \tau}$ & $\tau_{\tau}$ & $\tau_{\alpha \mu}$ & $\tau_{\mu}$ & $\tau$ & $\tau$ \\
\hline Nordeste & 1 & $-1,23$ & $-2,43$ & 2,13 & $-2,17$ & $-0,42$ & $-9,96^{a}$ \\
Sudeste & 1 & $-0,57$ & $-2,88$ & 2,92 & $-2,90$ & $-0,14$ & $-10,70^{a}$ \\
Sul & 1 & $-0,76$ & $-2,55$ & 2,45 & $-2,45$ & $-0,14$ & $-9,61^{a}$ \\
Centro-Oeste & 5 & $-1,08$ & $-2,48$ & 2,39 & $-2,38$ & $-0,01$ & $-5,40^{a}$ \\
\hline
\end{tabular}

Fonte: Dados da Pesquisa.

${ }^{a}$ significativo ao nível de 0,05 de probabilidade.

* Modelo $1-\Delta y_{t}=\alpha+\beta T+\eta y_{t-1}+\sum_{i=1}^{p-1} \phi_{i} \Delta y_{t-1}+e_{t}$

nas versões (a) com constante e tendência, (b) sem tendência,

e (c) sem tendência e sem constante.

** Modelo $2-\Delta \Delta y_{t}=\eta \Delta y_{t-1}+\sum_{i=1}^{p-2} \phi_{i} \Delta \Delta y_{t-1}+e_{t}$,

definido depois de constatada a não existência de termos deterministas.

Constatou-se, assim, que todas as séries temporais analisadas sobre salários de trabalhadores temporários são integradas de primeira ordem (estacionárias nas primeiras diferenças). Por isso, foram realizados os testes de co-integração para analisar a existência de relações de longo prazo. Os resultados da estimativa do modelo multivariado de Johansen (1988), representado na equação (2) da seção 2, permitem concluir que existe fraca relação de equilíbrio de longo prazo entre os salários dos trabalhadores temporários das regiões Nordeste, Sudeste, Sul e Centro-Oeste (tabela 11). Neste caso, existe um único vetor e apenas em um teste estatístico é significativo (teste traço).

Tabela 11

Resultados dos testes de co-integracão de Johansen dos salários dos trabalhadores agrícolas temporários- Regiões Nordeste, Sudeste, Sul e Centro-Oeste

\begin{tabular}{cccc}
\hline Hipótese Nula & Hipótese Alternativa & Traço & $\lambda_{\max }$ \\
\hline$r \leq 3$ & $r=4$ & $4,65^{N S}$ & $4,65^{N S}$ \\
$r \leq 2$ & $r=3$ & $18,40^{N S}$ & $13,74^{N S}$ \\
$r \leq 1$ & $r=2$ & $32,85^{N S}$ & $14,46^{N S}$ \\
$r=0$ & $r=1$ & $61,98^{a}$ & $29,13^{N S}$ \\
\hline
\end{tabular}

Fonte: Dados da Pesquisa.

Nota: ${ }^{a}$ significativo ao nível de 0,05 de probabilidade e

NS é não significativo. Os valores críticos para os testes Traço e

$\lambda_{\max }$ estão em Osterwald-Lenum (1992). O modelo estimado

foi com constante restrita, e ajustado com duas defasagens.

Novamente, visando uma maior robustez dos resultados obtidos, que sinalizam relação de equilíbrio de longo prazo entre os salários dos trabalhadores agrícolas temporários das diferentes regiões consideradas no estudo (Nordeste, Sudeste, Sul 
e Centro-Oeste), foram feitos testes de co-integração combinando as regiões duas a duas. Os resultados apresentados na tabela 12 corroboram os obtidos no teste de co-integração dos salários regionais tratados conjuntamente. Verificam-se, nessa análise de pares, relações de co-integração entre os salários dos trabalhadores agrícolas temporários do Centro-Oeste com o salário dos trabalhadores da mesma categoria das demais regiões e entre os salários dos trabalhadores do Nordeste com o dos trabalhadores das regiões Centro-Oeste e Sudeste. Se fosse considerado um nível de significância de 0,10, poderia-se concluir pela existência de co-integração também entre os salários dos trabalhadores do Nordeste e do Sul. ${ }^{4}$

Tabela 12

Resultados dos testes de co-integracão de Johansen dos salários dos trabalhadores agrícolas temporários - Regiões Nordeste (NE), Sudeste (SE), Sul (S) e Centro-Oeste $(\mathrm{CO})$

\begin{tabular}{ccccc}
\hline Regiões Testas & Hipótese Nula & Hipótese Alternativa & Traço & $\lambda_{\max }$ \\
\hline NE e SE & $r \leq 1$ & $r=2$ & $2,31^{N S}$ & $2,31^{N S}$ \\
& $r=0$ & $r=1$ & $19,51^{a}$ & $17,19^{a}$ \\
NE e S & $r \leq 1$ & $4,16^{N S}$ & $4,16^{N S}$ \\
& $r=0$ & $r=1$ & $17,63^{*}$ & $13,67^{*}$ \\
SE e S & $r \leq 1$ & $r=2$ & $4,75^{N S}$ & $4,75^{N S}$ \\
SE e CO & $r=0$ & $r=1$ & $19,58^{N S}$ & $14,83^{N S}$ \\
NE e CO & $r \leq 1$ & $r=2$ & $6,76^{N S}$ & $6,76^{N S}$ \\
& $r=0$ & $r=1$ & $25,97^{a}$ & $19,21^{a}$ \\
S e CO & $r \leq 1$ & $r=2$ & $2,65^{N S}$ & $2,65^{N S}$ \\
& $r=0$ & $r=1$ & $21,13^{a}$ & $18,49^{a}$ \\
& $r=0$ & $r=2$ & $4,03^{N S}$ & $4,03^{N S}$ \\
& $r=0$ & $r=1$ & $19,91^{N S}$ & $15,88^{a}$ \\
\hline
\end{tabular}

Fonte: Dados da Pesquisa.

Nota: ${ }^{a}$ significativo ao nível de 0,05 de probabilidade e NS é não significativo. Os valores críticos para os testes Traço e $\lambda_{\max }$ estão em Osterwald-Lenum (1992). Os modelos estimados foram com constante restrita, e ajustados com duas defasagens, exceto no caso do Nordeste e Sudeste (quatro defasagens.)

*Esses valores são significativos ao nível de 0,05 de probabilidade, mas são significativos ao nível de 0,10 de probabilidade.

A região Nordeste apresenta-se como fonte exportadora de mão-de-obra temporária, no sentido de deslocar o trabalhador, temporariamente, para outras regiões em busca de oportunidades de emprego no próprio setor agropecuário. Esta mobilidade ocorre sem que haja mudança das famílias, ou seja, há apenas deslocamento de alguns dos membros das famílias, quase sempre do sexo masculino, que aproveitam o trabalho sazonal nas demais regiões. Este tipo de mobilidade de

\footnotetext{
${ }^{4}$ Considerando os dados de 1966 a 1999, foi encontrada co-integração entre os salários dos trabalhadores temporários das regiões Nordeste e Sul ao nível de significância de 0,05. Essa redução da significância estatística da co-integração deve-se, provavelmente, à redução relativa no uso de trabalhadores temporários na região Sul na última década.
} 
mão-de-obra (que não se caracteriza como sendo migração) proporciona um certo nível de arbitragem nos salários dos trabalhadores temporários no longo prazo. A migração rural-urbana está fortemente associada à mobilidade intersetorial e mesmo que as famílias desses trabalhadores residam nas periferias das cidades de pequeno e médio porte e continuem exercendo atividades agrícolas isto não possibilitaria a arbitragem salarial entre as regiões. A mobilidade da força de trabalho que se ausenta do seu local de moradia para aumentar a oferta nas demais regiões - possibilita a arbitragem salarial e uma relação salarial de longo prazo.

As relações de co-integração observadas entre os pares (Sudeste, Centro-Oeste) e (Sul e Centro-Oeste) podem ser reflexos da arbitragem que o Nordeste gera sobre os salários dos trabalhadores temporários das regiões Sudeste, Sul e Centro-Oeste.

Os resultados da tabela 13 mostram que, entre os estados da região Nordeste, há fraca relação dos salários dos trabalhadores temporários ao longo do tempo, em razão de se ter observado um único vetor de co-integração e um só teste estatístico (traço) ter apontado relação de co-integração. Os mercados de trabalho agrícola dessa região apresentam particularidades que propiciam que os salários tenham comportamentos fracamente relacionados, refletindo, provavelmente, no comportamento da diferença de salários entre os estados de cada uma dessas regiões. As culturas predominantes nos estados do Nordeste que utilizam mão-de-obra temporária não são coincidentes, além de não haver ofertas de emprego que absorvam toda a força de trabalho disponível.

Tabela 13

Resultados dos testes de co-integracão de Johansen dos salários dos trabalhadores agrícolas temporários - Estados da Região Nordeste (Maranhão, Ceará, Rio Grande do Norte, Paraíba, Pernambuco, Sergipe e Bahia)

\begin{tabular}{cccc}
\hline Hipótese Nula & Hipótese Alternativa & Traço & \multicolumn{1}{c}{$\lambda_{\max }$} \\
\hline$r \leq 6$ & $r=7$ & $2,32^{N S}$ & $2,32^{N S}$ \\
$r \leq 5$ & $r=6$ & $9,21^{N S}$ & $6,89^{N S}$ \\
$r \leq 4$ & $r=5$ & $18,09^{N S}$ & $8,89^{N S}$ \\
$r \leq 3$ & $r=4$ & $35,45^{N S}$ & $17,36^{N S}$ \\
$r \leq 2$ & $r=3$ & $60,66^{N S}$ & $25,21^{N S}$ \\
$r \leq 1$ & $r=2$ & $93,71^{N S}$ & $33,05^{N S}$ \\
$r=0$ & $r=1$ & $133,20^{a}$ & $39,49^{N S}$ \\
\hline Fonte: Dados da Pesquisa. & \\
Nota: a significativo ao nível de 0,05 de probabilidade e \\
NS é não significativo. Os valores críticos para os testes Traço e \\
$\lambda_{\text {max }}$ estão em Osterwald-Lenum (1992). O modelo \\
estimado foi com constante restrita, e ajustados com três defasagens.
\end{tabular}

Nas regiões Sudeste, Sul e Centro-Oeste o grau de integração entre os estados dentro de cada região é maior relativamente ao verificado na região Nordeste. Os dois testes estatísticos indicam a existência de um único vetor de co-integração 
dentro de cada uma daquelas regiões (ver tabelas 14,15 e 16). A razão para isso é o fato de dentro de cada uma daquelas regiões haver maior grau de informação entre os trabalhadores temporários e maior similaridade entre as atividades agropecuárias.

\section{Tabela 14}

Resultados dos testes de co-integracão de Johansen dos salários dos trabalhadores agrícolas temporários - Estados da Região Sudeste (Minas Gerais, Espirito Santos, Rio de Janeiro e São Paulo)

\begin{tabular}{cccc}
\hline Hipótese Nula & Hipótese Alternativa & Traço & $\lambda_{\max }$ \\
\hline$r \leq 3$ & $r=4$ & $4,14^{N S}$ & $4,14^{N S}$ \\
$r \leq 2$ & $r=3$ & $10,77^{N S}$ & $6,64^{N S}$ \\
$r \leq 1$ & $r=2$ & $25,39^{N S}$ & $14,62^{N S}$ \\
$r=0$ & $r=1$ & $55,64^{a}$ & $30,25^{a}$ \\
\hline
\end{tabular}

Fonte: Dados da Pesquisa.

Nota: ${ }^{a}$ significativo ao nível de 0,05 de probabilidade e

NS é não significativo. Os valores críticos para os testes Traço e

$\lambda_{\max }$ estão em Osterwald-Lenum (1992). O modelo

estimado foi com constante restrita, e ajustados com duas defasagens.

Tabela 15

Resultados dos testes de co-integracão de Johansen dos salários dos trabalhadores agrícolas temporários - Estados da Região Sul (Paraná, Santa Catarina e Rio Grande Sul)

\begin{tabular}{|c|c|c|c|}
\hline Hipótese Nula & Hipótese Alternativa & Traço & $\lambda_{\max }$ \\
\hline$r \leq 2$ & $r=3$ & $5,96^{N S}$ & $5,96^{N S}$ \\
\hline$r \leq 1$ & $r=2$ & $19,03^{N S}$ & $13,06^{N S}$ \\
\hline$r=0$ & $r=1$ & $46,03^{a}$ & $27,01^{a}$ \\
\hline $\begin{array}{l}\text { Fonte: Dados } \\
\text { Nota: }{ }^{a} \text { signif } \\
\text { NS é não sign } \\
\lambda_{\max } \text { estão en }\end{array}$ & $\begin{array}{l}\text { Pesquisa. } \\
\text { tivo ao nível de } 0,0 \\
\text { cativo. Os valores cr } \\
\text { Osterwald-Lenum ( } 1\end{array}$ & $\begin{array}{l}\text { le probab } \\
\text { cos para } \\
\text { 2). O mo }\end{array}$ & $\begin{array}{l}\text { lade e } \\
\text { testes Traço e } \\
\text { lo }\end{array}$ \\
\hline
\end{tabular}

Tabela 16

Resultados dos testes de co-integracão de Johansen dos salários dos trabalhadores temporários - Estados da Região Centro-Oeste (Mato Grosso do Sul, Mato Grosso e Goiás)

\begin{tabular}{cccc}
\hline Hipótese Nula & Hipótese Alternativa & Traço & $\lambda_{\max }$ \\
\hline$r \leq 2$ & $r=3$ & $5,97^{N S}$ & $5,97^{N S}$ \\
$r \leq 1$ & $r=2$ & $25,07^{a}$ & $19,10^{a}$ \\
$r=0$ & $r=1$ & $49,81^{a}$ & $24,74^{a}$ \\
\hline Fonte: Dados da Pesquisa. & \\
Nota: a significativo ao nível de 0,05 de probabilidade e \\
NS é não significativo. Os valores críticos para os testes Traço e \\
$\lambda_{\text {max }}$ estão em Osterwald-Lenum (1992). O modelo \\
estimado foi com constante restrita, e ajustados com duas defasagens.
\end{tabular}


A figura 2 apresenta os valores das diferenças de salários dos trabalhadores temporários entre as regiões analisadas. De modo geral, a dispersão das diferenças salariais é muito maior do que o obtido para os trabalhadores permanentes (figura 1). Observando a figura, verifica-se que, na segunda metade da década de 80 , ocorreu uma maior estabilidade nas diferenças salariais entre as regiões, coincidindo com a unificação do salário mínimo em 1984.

Com era de se esperar, a região Nordeste apresenta maiores diferenças salariais em relação às demais regiões. Estas diferenças, quando comparadas às verificadas para os trabalhadores permanentes, é muito maior ao longo do período em analise (1966 a 2002). Esta situação deve estar muito mais associada à relação de trabalho menos estável desses trabalhadores, a qual permite maior flutuação dos salários, do que a outras variáveis, como a produtividade do trabalho. Nos anos 90 há redução das diferenças salariais entre as regiões com o setor agropecuário tecnicamente mais avançado, indicando um processo de convergência.

Figura 2

Relação salarial dos trabalhadores temporários entre as regiões brasileiras: nordeste (NE), sudeste (SE), sul (S) e centro-oeste (CO)

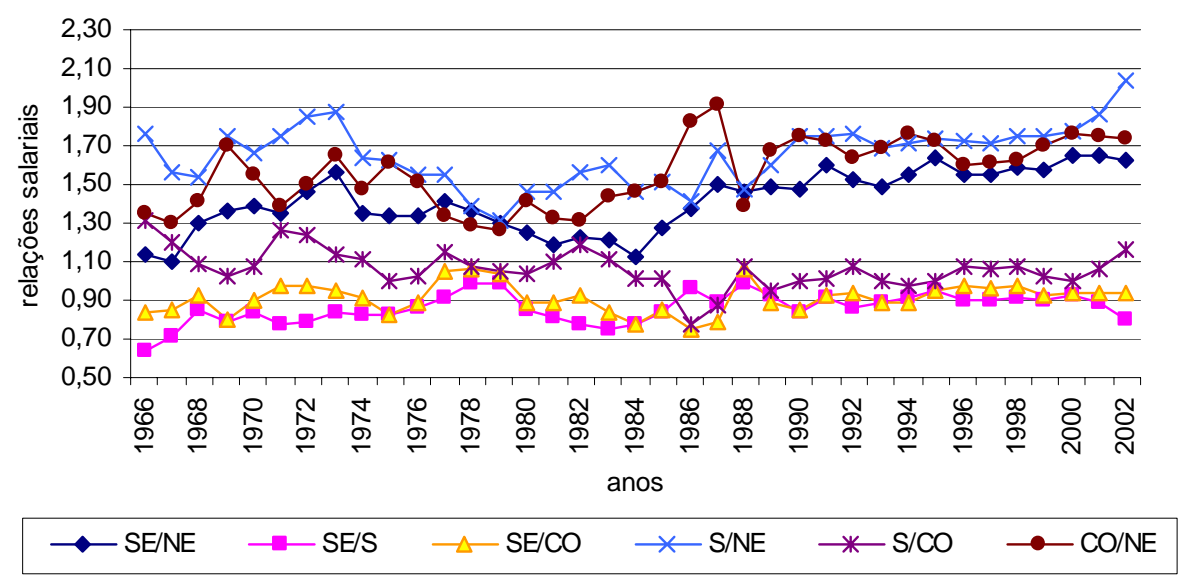

\section{Conclusões}

O presente trabalho procurou analisar as tendências de longo prazo nas diferenças de salários pagos na agropecuária. Para tanto, os trabalhadores foram desagregados em duas categorias: permanentes e temporários. 
Os resultados dos testes de co-integração indicam que não há relação expressiva de equilíbrio de longo prazo entre os salários dos trabalhadores agrícolas permanentes entre as regiões Nordeste, Sudeste, Sul e Centro-Oeste no período de 1966 a 1999. Esta situação deve-se ao fato da mobilidade inter-regional dos trabalhadores ter ocorrido - nos anos 60, 70, e 80 - principalmente por meio dos fluxos migratórios campo-cidade. Quando se verificou fluxo migratório inter-regional no sentido rural-rural, como foi o caso da migração do Sul para o Centro-Oeste, observou-se apenas fraca relação de longo prazo entre os salários dos trabalhadores dessas duas regiões, possivelmente pelo fato dessa migração ter sido expressiva só na década de 70. Outros fatores podem ter contribuído para a ausência de relações entre os salários dos trabalhadores agrícolas permanentes das diversas regiões consideradas na análise, que imprimem certa rigidez à remuneração dos trabalhadores.

Constatou-se a existência de relação de equilíbrio de longo prazo entre os salários dos trabalhadores permanentes dentro de cada região analisada. Além da possibilidade de existir algum grau de arbitragem em função dos deslocamentos dos trabalhadores, aspectos regionais devem ter propiciado a ocorrência de relações de equilíbrio de longo prazo entre esses salários dentro das regiões, podendo-se citar a estrutura fundiária, o salário mínimo vigente, a aptidão para diferentes atividades agrícolas, a produtividade do trabalho e o custo de vida. As relações de longo prazo para os salários desses trabalhadores permanentes ocorreram mesmo considerando a menor mobilidade locacional deles em relação à dos trabalhadores temporários. Outro aspecto que pode ter propiciado a existência de relações de longo prazo entre os salários dos trabalhadores permanentes dentro das regiões é o nível de informação desses trabalhadores a respeito do salário médio na sua região, que gera expectativas e busca de uma remuneração próxima a esse valor.

Os resultados da análise de cointegração para os salários dos trabalhadores temporários evidenciam que a região Nordeste é grande arbitradora de salário dessa categoria de trabalhadores em relação às demais regiões do Brasil. Isto ocorre devido à grande mobilidade de mão-de-obra sazonal do Nordeste com destino às demais regiões. As regiões Sudeste, Sul e Centro-Oeste apresentaram, dentro delas, relações de co-integração para os salários de trabalhadores temporários, o que se explica pelo fato dos trabalhadores temporários dentro de cada uma dessas regiões terem maior volume de informações sobre o mercado de trabalho, haver maior similaridade entre as culturas praticadas e maior mobilidade potencial.

É possível que, no futuro, as relações de arbitragem observadas para os salários de trabalhadores temporários se modifiquem se a tendência de uso decrescente desse tipo de trabalho continuar. 


\section{Referências}

Aguirre, B. M. B. \& Bianchi, A. M. (1989). Reflexões sobre a organização do mercado de trabalho agrícola. Revista de Economia Política, 9(1):31-46.

Alves, E., Lopes, M., \& Contini, E. (1999). O empobrecimento da agricultura brasileira. Revista de Política Agrícola, 8(3):5-19.

Arbache, J. S. (2000). Determinação e diferencial de salários no Brasil. In Fontes, R. \& Arbex, M. A., editor, Desemprego e Mercado de Trabalho: Ensaios Teóricos e Empíricos. UFV, Viçosa, MG. 343 págs.

Ávila, A. F. D. \& Evenson, R. E. (1995). Total factor productivity growth in the brazilian agriculture and the role of agricultural research. In Congresso Brasileiro de Economia e Sociologia Rural, pages 631-657. SOBER, Brasília. Anais.

Bacha, C. J. C. (1991). Determinação dos salários na agricultura. Revista Brasileira de Economia, 45(3):441-471.

Barros, A. L. M. (1999). Capital, produtividade e crescimento da agricultura: O Brasil de 1970 a 1995. Piracicaba. Tese (Doutorado) - Escola Superior de Agricultura "Luiz de Queiroz", Universidade de São Paulo.

Brant, C. V. (1979). População e Força de Trabalho No Desenvolvimento Da Agricultura Brasileira. CEBRAP, São Paulo. 33 págs.

Cacciamali, M. C. (1986). A legislação trabalhista no campo e sua aplicação entre os "bóias-frias" no estado de São Paulo: Uma contribuição para o debate. In Duarte, D. O., editor, Emprego Rural e Migrações na América Latina. Editora Massangana/Fundação Joaquim Nabuco, Recife.

Camarano, A. A. \& Abramovay, R. (1998). êxodo rural, envelhecimento e masculinização no Brasil: Panorama dos últimos cincoenta anos. In Encontro Nacional Sobre Migrações, pages 303-327. IPARDES, FNUAP, Curitiba. Anais.

Carvalho, D. (1993). Mercado de trabalho na agricultura brasileira: Década dos oitenta. Piracicaba. Dissertação (Mestrado) - Escola Superior de Agricultura "Luiz de Queiroz", Universidade de São Paulo.

Conceição, P. H. Z. (1998). Produtividade total e mudança técnica na agricultura brasileira, período 1955 - 1994. Piracicaba. Tese (Doutorado) - Escola Superior de Agricultura "Luiz de Queiroz", Universidade de São Paulo. 
Cunha, A. M. \& Maia, M. M. (1984). Modernização, tecnologia e emprego rural: Evidência da década de 70 na região centro-sul do Brasil. In Conferência LatinoAmericana de Economia Agrícola, pages 1-53. ESALQ, Piracicaba. Anais.

Dias, R. S. \& Bacha, C. J. C. (1998). Produtividade e progresso na agricultura brasileira: 1970-1985. In Congresso Brasileiro de Economia e Sociologia Rural 36, Poços de Caldas, pages 211-221. SOBER, Brasília.

Dickey, D. \& Fuller, W. (1979). Distribution of the estimates for autoregressive time series with a unit root. Journal of the American Statistical Association, 74:427-431.

Dickey, D. \& Fuller, W. (1981). Likelihood ratio statistics for autoregressive time series with a unit root. Econometrica, 49:1057-1072.

Enders, W. (1995). Applied Econometric Time Series. John Wiley \& Sons, Inc., USA.

Fuller, W. A. (1976). Introduction to Statistical Time Series. John Willer, New York.

Gasques, J. G. (1975). Oferta e demanda de mão-de-obra volante no estado de São Paulo. Piracicaba: Escola Superior de Agricultura "Luiz de Queiroz", Universidade de São Paulo. (Dissertação Mestrado).

Gasques, J. G. (1981). Uma análise dos fatores que afetam os salários na agricultura. São Paulo: Instituto de Pesquisa Econômica, Universidade de São Paulo. (Tese Doutorado).

Gasques, J. G. \& Conceição, J. C. P. R. (1997). Crescimento e produtividade da agricultura brasileira. Brasília: IPEA. 21p. (Texto para Discussão, 502).

Goodman, D. E., Sorj, B., \& Wilkinson, J. (1985). Agroindústria, políticas públicas e estruturas sociais rurais: Análise recente sobre a agricultura brasileira. Revista de Economia Política, 3(4):31-55.

Guerreiro, E. (1995). Produtividade do trabalho e da terra na agropecuária paranaense. Piracicaba, 136p. Dissertação (Mestrado) - Escola Superior de Agricultura "Luiz de Queiroz", Universidade de São Paulo.

Hamilton, J. D. (1994). Time Series Analysis. Princenton University Press, Princenton. New Jersey. 799p. 
Harvey, A. (1990). The Econometric Analysis of Time Series. MIT Press, Cambridge, Massachusetts. 387p.

Hoffmann, R. \& Jamas, A. L. (1990). A produtividade da terra e do trabalho na agricultura de 332 microrregiões do Brasil. In Congresso Brasileiro de Economia e Sociologia Rural, 28, Curitiba, pages 21-40. SOBER, Brasília. Anais.

Instituto Brasileiro de Geografia e Estatística - IBGE (1999). Pesquisa nacional por amostragem de domicílio. Rio de Janeiro: IBGE, 113p.

Istake, M. (1999). Transformações na agropecuária paranaense e suas implicações sobre o emprego e salários rurais: 1977-96. Piracicaba, 112 p. Dissertação (Mestrado) - Escola Superior de Agricultura "Luiz de Queiroz", Universidade de São Paulo.

Johansen, S. (1988). Statistical analysis of cointegration vetors. Journal of Economic Dynamic and Control, (12):231-254.

Johansen, S. \& Juselius, K. (1990). Maximum likelihood estimation and inference on co-integration - with application to the demand for money. Oxford Bulletin of Economics and Statistics, (52):169-219.

Lopes, H. F. (1995). Co-integração: Uma introdução. VI Escola de Séries Temporais e Econometria. Vitória, ES. (mimeo).

Mello, D. M. C. (1975). "Bóia-Fria": Acumulação e Miséria. Vozes, Petrópolis.

Osterwald-Lenum, M. (1992). A note with quantiles of the asymptotic distribution of the maximum likelihood cointegration rank test statistics. Oxford Bulletin of Economics and Statistics, 53(3):461-472.

Saylor, R. G. (1974). Procura e oferta de mão-de-obra agrícola no estado de São Paulo. Agricultura em São Paulo, 21(3):129-146.

Silva, J. G. (1999). O Novo Rural Brasileiro. UNICAMP/IE, Campinas. 153 págs.

Staduto, J. A. R., Bacchi, M. R. P., \& Bacha, C. J. C. (2002a). Uma análise de longo prazo dos salários dos trabalhadores agrícolas permanentes do Brasil. Anais do XL Congresso Brasileiro de Economia e Sociologia Rural. Passo Fundo, 28 a 31 de julho de 2002. CDROM.

Staduto, J. A. R., Bacha, C. J. C., \& Bacchi, M. R. P. (2002b). Determinação dos salários na agropecuária brasileira. Pesquisa e Planejamento Econômico, 32(2). 
Staduto, J. A. R. \& Freitas, C. A. (2001). Uma avaliação da mudança estrutural da produção agrícola brasileira no período 1959-1995. In Congresso Brasileiro de Economia e Sociologia Rural, 39, Recife. SOBER, Recife. Anais.

Staduto, J. A. R., Shikida, P. F. A., \& Bacha, C. J. C. (2002c). Alteração na composição da mão-de-obra assalariada na agropecuária brasileira - período pós 1960. Anais do VI Congresso da Associação Latino-Americana de Sociologia Rural. Porto Alegre, novembro de 2002. Texto em CD-ROM, p. 2828 a 2845. 